\section{RADICAL CURE OF HERNIA.}

SYMPTOMS OCCURRING SIMULATING PERITONITIS.

By JOHN REDFERN DAVIES, Esq., M.R.C.S. ENG., SURGEON TO THE BIRMINGHAM WORKHOUSE INFIRMARY.

THE following case, from symptoms of a peculiar and doubtful nature arising during the process of cure, may be worthy of record amongst the numerous other facts that are being elicited in the present day respecting the radical cure of hernia:-

S. H- a - aged seventeen, had been the subject of a direct inguinal hernia, of about the size of a walnut, for three years. It was operated upon by Wood's method, the only difference being the employment of scissors instead of a knife in the process of the subcutaneous dissection, and the intervention of a circular piece of india-rubber beneath the wooden disc. She progressed very favourably, the wires being withdrawn on the fifth day, the parts then looking well, and all kut united by the first intention.

The day following the patient was still doing well. In the evening, about ten P.M. I was informed she was very ill, and, upon seeing her, found her lying upon her back; knees drawn up; countenance anxious; pulse 120; skin hot and parched; complaining of pain all over the abdomen, but chiefly just above the pubis, where she could not bear the slightest pressure. The wound looked well, and there was less pain there than elsewhere. I knew not what to think. The symptoms were those of peritonitis; but how caused I coudd not conceive. Hot fomentations and large doses of ipecacuanha and opium were administered. In four hours afterwards she was in a profuse perspiration, and somewhat easier; and in another four hours the menstrual discharge appeared for the first time, and very copiously. At the same time all the symptoms rapidly abated, and by morning everything unpleasant had subsided, save that the wound now gaped, and there was a little suppuration from it.

A similar train of symptoms, but much less in degree, again appeared upon the second menstrual flow, which occurred in about two weeks after the first. The radical cure of the hernia was, however, in nowise affected, and is as perfect as could be wished:

I would remark that the use of scissors instead of the knife very muck facilitates the subcutaneous dissection of the parts, effeeting it much more rapidly and evenly.

Birmingham, September, 1859 .

\section{CAN THE GARDEN SLUG LIVE IN THE HUMAN STOMACH?}

By DAVID DICKMAN, Esq., M.R.C.S.

SARAH ANN C- aged twelve years, had, for the last two months, complained of feeling sick at times, particularly after meals. On the 5th of August last, she vomited up a large garden slug, which was alive and very active. On the 6th, she brought up two, both alive; and on the night of the 7th she was seized with violent vomiting and relaxation of the bowels, and threw up five more, of various sizes, the smallest two inches long, and all alive.

On the morning of the 8 th, when I first saw her, vomiting and purging had ceased, and she complained of great pain in the left region of the stomach, and headache. I gave her opiate powders, which relieved her in every way till the afternoon of the 9 th, when she felt something crawling up her throat. This sensation brought on the most violent efforts of vomiting to expel what she felt at the upper part of her throat, and she frequently introduced her fingers to seize what she felt, but did not succeed. I happened to call just when all this suffering was beginning to subside, at which time the sensation was felt lower-about half way between the mouth and the stomach. As expulsion by vomiting seemed hopeless, it occurred to me that ammonia and camphor might destroy the creature, and that the digestive powers of the stomach would do the rest when the animal was dead. The dose was repeated every four hours for two days, and afterwards three times a day for two days more, with entire snceess. An ape- rient powder was given every night. After the first dose of the ammonia and camphor, all sensation of movement ceased; and she now appears as well as ever she was.

During the summer she had gone frequently into the garden and eaten freely of its produce, especially of lettuces, of which she was very fond. It appears to me that a family of very young slugs had been feeding on the lettuces, which the child had swallowed with very little mastication, and the gastric juice not being strong enough to act on them when alive, they fed and grew in their new habitation to their usual dimensions. During the time they must have been in the stomach, she was fonder than ever of vegetables and fruits, and would put aside the meat on her plate, and eat the vegetables only.

The three slugs that came up first were not preserved; but, at my request, the five others have been kept alive, and fed on vegetables, which they preferred being cooked, having at first refused to eat them raw. They are now fed on raw vegetables.

Another circumstance connected with my interesting patient is, that she was born without the left hand. During pregnancy the mother was frightened by a porcupine that an organ boy had in the street; and an impression ever after remained on her mind that something would not be right with the child's hand.

Porchester-place, Oxford-square, Sept. 1859.

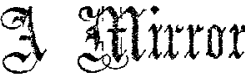

OF THE PRACTICE OF

\section{MEDICINE AND SURGERY IN THE}

\section{HOSPITALS OF LONDON.}

Nulla est alia pro certo noscendi via, nisi quam plurimas et morborum et dissectionum historias, tam aliorum proprias, collectas habere et inter se comparare.-MokgagNI. De Sed. et Caus. Aorb., lib, 14. Proœmiun.

\section{ST. GEORGE'S HOSPITAL.}

STRANGULATED FEMORAL AND UMBILICAL HERNIA IN WOMEN-THE LAST ASSOCIATED WITH PREGNANCY; HERNIOTOMY SUCCESSTUL IN TWO OUT OF FOUR CASES.

\section{(Under the care of Mr. TATUM and Mr. P. HEwETT.)}

ThE first three of the following cases were such as are usually met with in women; that is to say, the protruding portion of bowel consisted of a small knuckle, which had passed through the femoral ring. A fatal result ensued in the first and third: in the former, from the hæmorrhage poured out by a branch of the epigastric; in the latter, from the extreme collapse which was present even before an operation was performed. The fourth case was one of umbilical rupture, accompanied by pregnancy, but which did not prevent a good recovery, although there was some difficulty experienced in arresting troublesome hæmorrhage, a peculiarity which was present also in the second case. In all, the sac was opened.

For the notes of these cases we are indebted to Mr. George F. Cooper, surgical registrar to the hospital.

CASE 1.-A. T- was admitted, under Mr. Prescott Hewett's care, on the 4th of January, for strangulated femoral hernia. She had had a hernia in the left side for the last six months, but it could be always easily reduced. She never wore a truss. Four days ago, she found she could not return it; sickness soon came on, and has continued since.

On admission, she was in a state of great collapse, having constant stercoraceous vomiting, and acute tenderness over the abdomen and hernial tumour. An operation was immediately performed. The sac was opened, and found to contain a small knuckle of gut, which was much congested, and a small piece of omentum, which was removed; the stricture was very deep and tight. Directly after the operation, the bowels acted very copiously. She was given twenty minims of tincture of opium.

Jan. 7th. - She was a little sick this morning. The tenderness of the abdomen was rather less, though still severe. There was considerable tympanitis. Her tongue was moist, skin 
cool, and pulse 100 and jerking. The wound looked healthy, and had partially healed. She was given calomel and opium every six hours.

8th.-Was delirious this morning; her pulse was 120, and very weak; tongue dry; and she was in a very low state. There was more tenderness over the abdomen. The edges of the wound were of a dark colour. The calomel and opium were repeated every three hours, and she was also given brandy and port wine; but towards evening she sank.

The autopsy showed the following:--The peritoneal cavity contained much blood, reaching as high as the small omentum, and coating the various viscera; but the largest quantity was in the pelvis. The gut and omentum that had been strangulated were lying at a distance from the femoral ring, five feet from the ileo-cæcal valve, and were evidently recovering them. selves. No vessel could be found wounded, except a very small one which was given off from a branch of the epigastric artery.

CASE 2.-A. F-_, aged fifty-two, was admitted, on July i0th, under Mr. Prescott Hewett's care, for strangulated femoral hernia. She had had a hernia on the left side for the last ten years, for which she had always worn a truss. When it came down she could never return it herself, always requiring the aid of medical man; and this reduction gave her much pain. Five years ago she was in Guy's Hospital for symptoms of strangulation, but the gut was then returned by means of a hot bath and taxis. It had not been down since last Tovember until three hours ago, and directly afterwards sickness came on. Hot baths and taxis were tried, but in vain; go, five hours after the strangulation took place, an operation was performed. The sac was opened, and found to contain nothing but a small knuckle of intestine, not much congested. Directly the stricture was divided, which was the inner portion of Poupart's ligament, and the gut returned, a jet of blood took place, which was of such a size that it came evidently from some considerable vessel. Mr. Hewett managed to ligature one end of the artery by simply drawing down the sac of the hernia, by which means it was exposed; but the other end he could not get hold of at all until he had cut through and everted Gimbernat's ligament, and then just beneath this he saw the vessel bleeding, which was accordingly secured.

The woman did very well, and on August $17 \mathrm{th}$, thirty.eight days after the operation, she left the hospital.

CASE 3.--E. $Y$ - , aged fifty-one, was admitted on August $17 \mathrm{th}$, under the care of $\mathrm{Mr}$. Tatum, for severe constipation and stercoraceous vomiting, she having suffered from the former for the last six days, and from the latter for about twenty-four hours. Until the day of her admission she had applied to no one; but, on that day, she called in a medical man, who gave her an enema, but the whole of it was directly returued. She stated she had had a hernia for four or five years past, but had never worn a truss. On admission, besides the constipation and vomiting, she was in a state of great collapse, had some tenderness over her abdomen, and complained of a tender swelling in the right groin, which was examined, and declared to be an inflamed gland. Nothing could be felt below this; but, on account of the extreme urgency of the symptoms, an operation was proposed. She was then quite cold; her pulse covld scarcely be felt; in fact, she was moribund. Beneath the intlamed gland, a small aqueous cyst was found, and still deeper, a small strangulated piece of intestine. The sac was opened and found to contain about half an ounce of milky fluid; a knuckle of intestine of the size of a filbert, not very dark in colour, and which became even lighter before returned; and a swall piece of omentum, which was adherent to the sac, and was accordingly left there. The woman did not rally at all, and in about half an bour she died. An autopsy showed some peritonitis. There was also a band of Iymph encircling three parts of the gut, which was recovering itself, showing the original stricture.

CASE 4.-H. M-, aged thirty-nine, was admitted on July 30th, under Mr. Prescott Hewett, for strangulated umbilical hernia. The patient stated that, seven or eight years ago, whilst pulling a box from beneath a bed, she ruptured herself in the umbilical region, since which time she had always worn a bandage to support the hernia, but it never returned into the carity of the abdomen. It never gare her any inconvenience till a month ago, when she felt some pain in the tumour, and since then it had gradually increased in size; it had also been retting painful and harder to the touch. On admission, she sail thit she was four months advanced in pregnancy; she had had two children since she had been ruptured, but they had never affected the hernia in any way. The bowels had not acted for five days, and since then she had been frequently sick. An operation was performed immediately. On dividing the stricture, which consisted of a large piece of omentum en. circling a small knuckle of the transverse culon, a vessel of the size of a crow-quill was cut across. The divided ends were so situated that there was some considerable difficulty in securing them; for one was attached to the omentum, whilst the other was lying on the surface of the gut, thel eby rendering it very difficult to take up the latter without injuring the bowel. A little sloughing of the integuments followed the operation, and slight peritonitis; but she soon recovered from these, and on August 30 th left the hospital.

\section{GUY'S HOSPITAL.}

\section{U U COCYTHAMIA SPLENICA.}

(Under the care of Dr. WILISS.)

To the student who has to make himself familiar with the different varieties of disease, it is important sometimes to be enabled to examine a typical case, especially when it may happen to be one of the rarer forms. This opportunity is at the present time afforded by a young man twenty years of age (but who has the appearance of a lad of fifteen), in Guy's Hospital, who was admitted on the 15th of July, and who is labouring under the disease described by Dr. Hughes Bennett, of Edinburgh, as Leucocythcemia, which is characterized by an excess of white corpuscles in the blood, supposed to depend upon disease of the spleen. In this patient, who is from Newham, in Sussex, there is considerable enlargement of the spleen (which is quite prominent), associated with an excess of white corpuscles in the blood and a normal quantity of the red. No other diseased condition of body has been observed, although at the present time he has a cough, resulting from a recent cold. He has not suffered from ague, but is now taking sixgrain doses of guinine every four hours, with the application of the compound iodine ointment to the left side over the enlarged spleen. This affection has the name of splenica affixed to it to distinguish it from the Ancemia lymphatica, a disease which was illustrated in our "Mirror" of the 27th August, and in which, as we had occasion to mention, there is no excess of white corpuscles. The expression "leucocythæmia Iymphatica," therefore, is contradictory in itself, and must yield to the one adopted by Dr. Wilks, which we have already brought before the notice of our readers.

CARCINOMATOUS GROWTH OVER THE FRONT PART OF THE CRANIUII; SUCCESSFUL REMOVAL.

(Undex the care of Mr. Bevant.)

At first sight, the series of irregular prominences over the front part of the head of the patient who was the subject of the following case might have been taken for a number of sebaceous tumours of the scalp on the eve of suppurating. Very shortly after operative proceedings were conmenced, their true nature was discovered to be carcinomatons, and as much of the disease was taken away as the safety of the patient permitted. A wound exhibiting less promise of healing we have seldom seen; nevertheless, as stated in the notes of the case, the edges of the diseased shin were the first to mite by adhesion, and ultimately the woman left the hospital quite well, with no ap. pearance of a return of the disease, although it must be looked for at a later period.

H. C-, a healthy-looking woman, aged twenty-four, was admitted under the care of Mr. Bryant on the lst of June last. She had always enjoyed good health, and three years previonsly she first observed a tumour over the left frontal eminence, about the size of a small nut, and quite movable. Two or three months afterwards she discovered several others over the left frontal bone, and these hare been gradually enlarging.

When admitted, there was a large irregular tumour oyer the left parietal bone, about the size of a fist; it presented an uneven and nodular surface, was closely connected with the integument, and arpeared to be tightly bound down to the skull. Upon manipulation, it gave a tense, semi-elastic sensa. tion, and caused but little pain.

At the patient's express wish, the tumour was excised, althongh its character was very doubtful. On the first incision, the nature of the growth was clearly manifested. The skin was in parts infitirated with carcinomatons material, and the bone was exposed and rough. As much of the trimour as could 